\title{
A REAL-TIME APPROACH TO EVALUATE OCCUPANTS' THERMAL COMFORT IN THE INDOOR ENVIRONMENT
}

\author{
Mustafa Al-Adhami ${ }^{1}$, Song $\mathrm{Wu}^{2}$ and Elham Delzendeh ${ }^{3}$
}

\begin{abstract}
Building performance analysis applications have focused on the evaluation of specific designs based on static, uniform indoor environments. In reality, people live in a dynamic environment, neither indoor environments nor building occupants are static, and that would make thermal sensation experienced by an occupant in a building unstable and challenging to evaluate through the time. The cur-rent field survey methodology to evaluate thermal comfort in buildings according to Performance Measurement Protocols for Commercial Buildings (PMPCB) is based on instrumental measurement of indoor climate and questionnaires to be answered by building occupants in a specific space at the exact time. Some studies have questioned this approach due to the inconsistency of physical measurement, sampling procedures, and doubtful estimations of some other variables. These are likely to contribute to the incredibility of the survey and possibly affect the overall prediction accuracy.
\end{abstract}

Nowadays, the advancement of IoT technology has the potential to transform human-building interaction and improve building energy performance. It has been estimated that the connected IoT devices are around 9 billion worldwide, and this number expected to grow to reach 50 billion by 2020. In the built environment, the ability to control building indoor environmental variables can have a substantial impact on improving indoor environmental quality and reducing energy consumption, such control mostly achieved by using sensor technology.

Thus, this paper presents a unique approach to measure real-time human thermal comfort in the indoor environment. The proposed approach can predict occupants' thermal satisfaction level of an indoor environment throughout the building's operation. The implementation of environmental sensors and a pilot run to evaluate thermal satisfaction in real-time has been tested. The thermal model in ASHRAE standard 55 has used to evaluate thermal comfort.

Keywords: Human thermal comfort, Smart buildings, Internet of things (IoT), Predicted mean vote (PMV), Built environment, Climate change, Building energy efficiency

\section{INTRODUCTION}

Nowadays, climate change is the biggest threat to human civilization, and it is happening as a result of human activity. Since the industrial revolution, the increase in Greenhouse Gas Emissions (GHGs) has led to a rise in global temperatures. The primary source of GHGs is from burning fossil fuel-based energy. Reducing the amount of energy required in our everyday life can significantly cut down human impact on the environment. The

PhD student, University of Huddersfield, Huddersfield, UK, Mus.Adhami@hud.ac.uk

Professor, University of Huddersfield, Huddersfield, UK, S.Wu@hud.ac.uk

Lecturer, University of Huddersfield, Huddersfield, UK, E.Delzendeh2@hud.ac.uk 
built environment (BE) considered as one of the largest emitters of GHGs and a primary contributor to climate change (Architecure2030, 2018, DOE, 2010, Asadi et al., 2012). Globally, buildings account for $40 \%$ of global energy consumption and contribute to more than $30 \%$ of CO2 emissions (Costa et al., 2013). This has led to a massive concern in the research community to conduct numerous studies to improve building energy performance in the $\mathrm{BE}$, on new buildings, in design and construction of building envelopes such as thermal insulation (Pan et al., 2012, Joudi et al., 2013), lifecycle analysis (Asif et al., 2007) and optimization (Lam and Hui, 1996); on renovation of existing buildings (Chantrelle et al., 2011); and on optimization and control of HVAC and lighting systems (Mary Reena et al., 2018, Brooks et al., 2015).

The increase of energy demand in the BE connected to building occupants and the necessity of providing better comfort conditions, thermal comfort, visual comfort, acoustic and air quality (Pérez-Lombard et al., 2008, Nguyen and Aiello, 2013). Previous studies have shown the thermal conditioning system is among the major of energy enduse in the BE; it is responsible for about $50 \%$ of total energy consumption especially in non-domestic buildings (Pérez-Lombard et al., 2008, Chua et al., 2013, Ma et al., 2019). Another study on the evaluation of indoor environmental quality (IEQ) has shown thermal comfort satisfaction is highly important by building occupants and has a substantial impact on energy efficiency compared to other comfort needs (Frontczak and Wargocki, 2011). Accordingly, understanding thermal comfort implications on energy efficiency in buildings is essential not only to save energy and cut down energy bills, but it has a vital factor to mitigate human impact on global warming. As a result, several assessments and rating programs worldwide formed to promote sustainability and green buildings such as BREEAM, LEED and ENERGY STAR and becomes prevalent in the BE. Furthermore, architects and engineers use BIM and energy simulation tools to predict and improve building performance during the design stage of a building's lifecycle. Nonetheless, during building operations, where buildings consume up to $84 \%$ of total energy use in its lifecycle (DOE, 2010, Becerik-Gerber et al., 2011), buildings experience several unexpected factors that affect energy performance and occupants' thermal satisfaction such as sophisticated use of electrical equipment or occupants behavior.

Measuring thermal comfort in operational buildings is quite complicated and requires an in-depth perception of the environmental factors affects occupancy thermal satisfaction and cause overuse of energy. Most of the researchers have used the PMV index to evaluate thermal comfort in the indoor environment. This model also adopted by most of the standard and energy simulation tools. PMV index takes six parameters. Namely temperature, humidity air velocity means radiant temperature, metabolic rate clothing insulation. The knowledge of existing standards to evaluate IEQ is an example of this complexity. Accordingly, most works in this area carried out a qualitative analysis based on people performing some activity and answering a questionnaire.

Therefore, this paper aims to present an innovative approach to measure occupants' thermal comfort in the indoor environment and predict energy-use in real-time. The wireless sensor technology used to obtain environmental information, including Ambient temperature, relative humidity and air velocity at every single zone of the indoor environment. The proposed approach does not affect room layout or occupant's activity in the space.

\subsection{Thermal comfort in the built environment}

Thermal comfort is an essential factor in building design and in operating of indoor environment and its effect directly to occupants' satisfaction and energy consumption. 
Moreover, the energy used to provide thermal satisfaction is high; around $70 \%$ of primary energy use in commercial buildings goes for heating and cooling systems.

The reason for this poor performance related to several factors in the design and operation of the building. Such as building envelope design, the efficiency of the mechanical system and controls. Besides, there is a limitation or weak undressing among designers and building operators about the range of factors that are possibility affect the indoor thermal condition. Understand thermal comfort condition can create an excellent opportunity to save energy while maintain or even improve the level of occupant satisfaction.

Introducing such approach can give a clear understanding of how human response to the indoor climate variables. The current thermal comfort prediction tool can support the designer and building operators to understand human thermal comfort. However, these tools are static and based on manual measurement/input depends on designer/operators understanding of indoor climate variables.

The main objective of this paper is to present a novel approach to evaluate thermal comfort according to ASHRAE standard 55 in a single zone. Different from other thermal comfort tools, the main feature of this approach is to evaluate occupancy satisfaction and predict energy-use in real-time. The implementation of this approach can benefit architect, engineer and building operators and better understand thermal comfort.

\subsection{Sensor technology}

Nowadays, the advancement of IoT technology has the potential to transform the BE and the way building occupants interact with their surroundings. It has been estimated that the number of connected IoT devices are about 9 billion worldwide, and this estimate is expecting to grow to reach more than 50 billion in the next few years (Gubbi et al., 2013). In the $\mathrm{BE}$, the ability to control environmental variables can have a substantial impact on improving the indoor environment and reducing energy consumption, this method of control often performed by using sensor technology (Dong et al., 2019). Several sensors are being used in the BE, whether to understand occupants behavior pattern or to study the characteristic of the indoor environment. In building operation, these sensors can be categorized into three types; a) occupancy sensors to collect data from building users such as Passive Infrared Sensor (PIR) and Ultrasonic sensor, b) Sensors that can be used to collect data from the environment such as temperature, humidity and $\mathrm{CO} 2, \mathrm{c}$ ) Personal IoT sensors such as wearable sensors, heart rate, etc. A smart sensing system for thermal comfort can be classified into two classes, 1) human centre studies and 2) environmental measurement.

In the area of in human-centric design where age, gender and body mass are considered to determine individual thermal comfort, ambient temperature sensor and wearable are used. One of the biggest challenges in these studies is that individuals' thermal sensation is varied among occupants, and there is no fixed point in which all occupants feel comfort (Abdallah et al., 2016, Liu et al., 2013, Linhart and Scartezzini, 2011, Corgnati et al., 2008). To this end, Yun and Won (Yun and Won, 2012) introduce a personal comfort system to measure individual thermal comfort and save energy using developed with the integration of temperature, humidity, and air velocity sensors, the char works as a macro-zone controller. (Sardini and Serpelloni, 2010) uses a wireless sensor network (WSN) to determine the indoor temperature. The sensor attached to the electromechanical generator, which is powered by the indoor air velocity. 
This research is looking onto design a real-time approach enables researchers, building's operator to collect environmental parameter and occupants' thermal satisfaction of a single zone in real-time for better decision making and avoid unnecessary energy consumption.

\section{Methodology}

Usually, building performance analysis applications have focused on the evaluation of specific designs based on static, uniform indoor environments. People live in a dynamic environment, neither indoor environments nor building occupants are static or uniform, and that would make thermal sensation experienced by an occupant in a building unstable, complicated and nearly impossible to evaluate. Moreover, thermal comfortenergy conservation requires an advance understanding of the occupant's comfort level in the indoor environment.

This study has established a new approach of thermal comfort-energy sensing using a developed IoT sensor and data analytics technique using a machine learning (ML) regression model to predict the energy-consumption in real-time. This approach can help the building's operator to evaluate occupant's thermal satisfaction and make the building more energy efficiency. Although many design measurements considered building energy performance factors, finding the right balance between energy performance and occupancy thermal satisfaction in the operation of buildings is absolutely challenging. The current thermal comfort model in the international standards is used for evaluation of the indoor environment for a short period. Furthermore, there is a weak understanding of the relationship between occupants' thermal comfort and the amount of energy consumption related to them.

The thermal comfort-energy evaluation approach proposed in 'Erro! Fonte de referência não encontrada.' contains two modules. The first module is the evaluation of occupants' thermal comfort, which includes the characteristics of the indoor environment associated with thermal comfort returned by the developed IoT sensors. The data collected from the sensors are being used in the thermal comfort model in ASHRAE 55 standard to predict the level of occupant's satisfaction. A function has been developed to calculate PMV values in real-time based on the tool published by CBE University of California (Schiavon et al., 2014). However, this study has only considered the environmental parameters for the evaluation of thermal comfort, the personal factors are established based on the function of the space to set the level of activity, and the time of the year to set the type of clothing insulation.

The second module is the energy prediction. The prediction module consists of data generation and data machine learning. In order to predict the energy performance of a single zone in the building, an energy simulation tool has been used to generate synthetic data for that zone, considering all the possibilities of energy-use. in the simulation two types of data used as input static and parametric. Static data include 1) the energy model of the building considering all the properties of building components construction and the type of opening; 2) weather data information.

Parametric data include operation schedules for heating and cooling, occupancy schedule, and humidity control. This study has focused on the source of energy from the heating and cooling system in the building. Thus, any source of energy not related to the thermal conditioning system in the building has been disabled in the execution of the simulation, such as lightings, computers, and office equipment. 


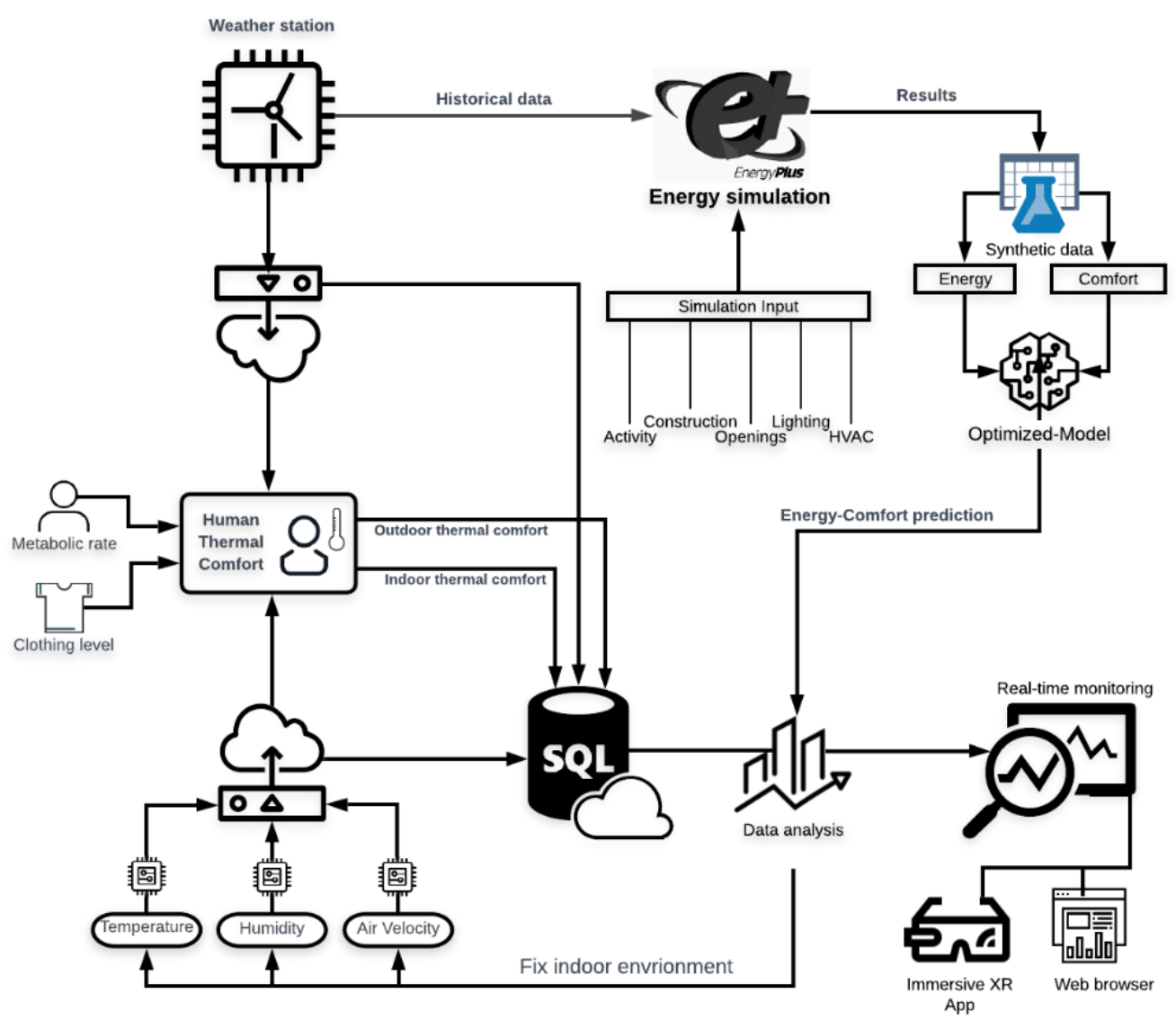

Figure 1: Energy-thermal comfort evaluation approach

\section{DESIGN OF REAL-TIME THERMAL COMFORT EVALUATION APPROACH.}

There are several tool and applications used to measure thermal comfort, such as climate consultant, Ecotect weather tool, Designbuilder, AHERAE thermal comfort too(Hudson and Velsaco, 2018). These applications need weather files which include one-year historical data. The main feature of these tools is to help read and understand weather data and show a summary of the selected weather file. It enables users to suggest strategies and techniques for better energy efficiency building, each of which based on its climate. In general, it centres on climate analysis rather than human thermal comfort, Moreover, it does not reflect the latest standard (Schiavon et al., 2014).

To this end, there is a need to developing a thermal comfort sensor that can aid building users and operators to understand occupants' thermal behaviour and assist them in applying the right strategies to minimize energy end-use. Thus, this study has proposed a real-time thermal comfort evaluation approach to predict energy consumption in the indoor environment.

\subsection{System architecture}

The proposed system can be divided into three layers: a) data acquisition using IoT sensors (Physical); b) data storage and data processing (back-end software), and c) data visualization (front-end software) see 'Erro! Fonte de referência não encontrada.' . 


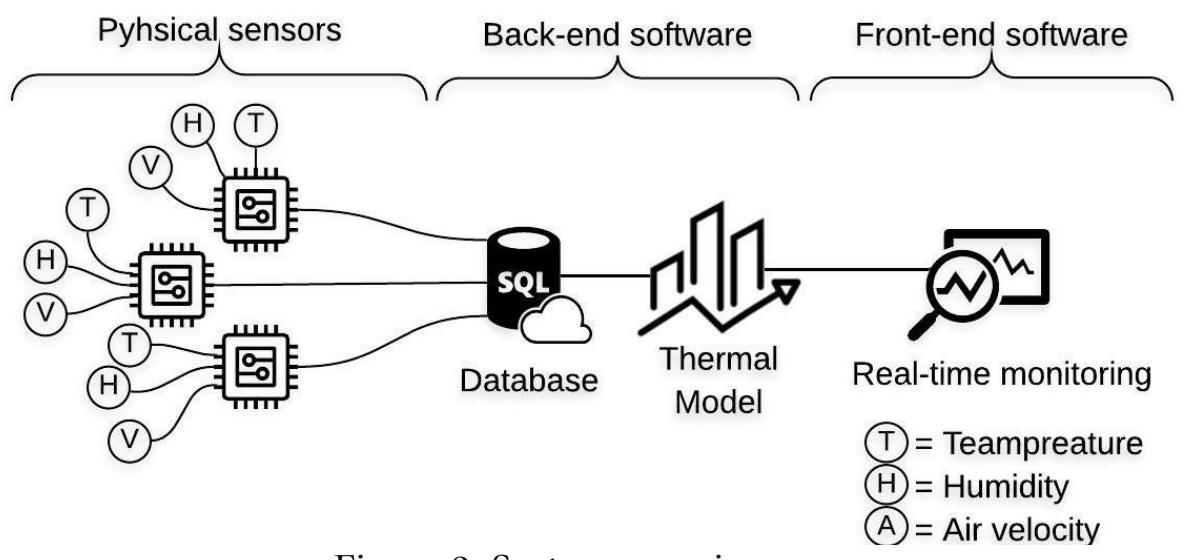

Figure 2: System overview

The physical layer includes environmental sensors to measure attributes from the indoor environment. The implementation consists of commercially available sensors to capture human thermal comfort environmental-related data through a Wi-Fi module that provides two-way data transmission, sent and receive. The sensors used in this study include temperate, humidity, air velocity, and Wi-Fi module (see Figure 3). All environmental sensors are powered by five voltage from a power bank using a standard Universal Serial Bus (USB) cable and connected to the internet using the Wi-Fi module.

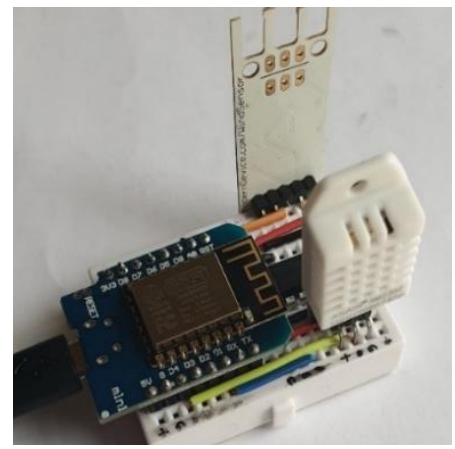

Figure 3: Thermal comfort sensor

The back-end software includes client read values from physical sensors over Wi-Fi and transmit it every 30 seconds. The client sends data from sensors and stores them in the cloud database. The data is stored in a separate table for each type of sensor in the cloud. This study is also using web page programming languages, HTML, JavaScript, and jQuery to control the data. Furthermore, this study has developed a thermal comfort model based adopted from CBE's comfort calculator following ASHRAE standard 55. The developed model receives environmental values from sensors temperature, humidity, and air velocity and evaluates occupants' thermal satisfaction. In the developed thermal comfort model personal values metabolic rate and clothing level are fixed according to the general activity in the space and the season of the year see Erro! Fonte de referência não encontrada..

The front-end software is using data stored in the cloud database for representation and user interaction. A flexible visualization technique is required to accommodate sensors data. There are several visualization techniques presented by previous studies that can be utilized for representation. An immersive visualization technique is still under development. The proposed thermal comfort evaluation system shows one of the IoT applications. It enables building users to observe the level of occupants' satisfaction in space in real-time. 
Table 1: Example of clothing insulation and metabolic rate values

\begin{tabular}{lclc}
\hline \multicolumn{1}{c}{ Activity } & $\begin{array}{c}\text { Metabolic } \\
\text { rate (met) }\end{array}$ & \multicolumn{1}{c}{ Clothing level } & $\begin{array}{c}\text { Insulation } \\
\text { values (clo) }\end{array}$ \\
\hline Reading seated & 1.0 & Typica summer indoor & 0.5 \\
Typing & 1.1 & Trouser, long sleeve shirt & 0.61 \\
Standing relax & 1.2 & Jacket, Trouser, long sleeve shirt & 0.96 \\
Walking & 1.7 & Typica winter indoor & 1.0 \\
\hline
\end{tabular}

\subsection{Predicted Mead Vote in thermal comfort calculator}

The proposed thermal comfort calculated in this study is based on the classic steadystate model for air-condition spaces proposed by Fanger, Predicted Mean Vote (PMV) index model (Fanger, 1970). The PMV model aims to predict the thermal sensation of occupancy in mechanical ventilated space. Fanger's model measured using four environment factors and two personal factors. The environmental-related factors are temperature, mean radiant temperature, air velocity, and humidity. The personals factors are metabolism and clothing. The calculation of the PMV values, as follows (Fanger, 1970).

$P M V=\left(0.028+0.3033 e^{-0.036 M}\right) \times L$

$L=(M-W)-3.05 \times 10^{-3}\left[5733-6.99(M-W)-P_{a}\right]-0.42[(M-W)-$

58.15-1.7 $\times 10-5 M 5867-P a-0.0014 M 34-t a-3.96 \times 10-8$ fcltcl+2734-tr+273

4-fclhc $(t c l-t a)$

$t_{c l}=35.7-0.028(M-W)-0.155 I_{c l}\left\{3.96 \times 10^{-8} \times f_{c l}\left[\left(t_{c l}+273\right)^{4}+\right.\right.$

tmrt+2734+fcl $\times h c(t c l-t a)\}$

$$
\begin{gathered}
h_{c}= \begin{cases}2.38\left(t_{c l}-t_{a}\right)^{0.25}, & \text { if } 2.38\left(t_{c l}-t_{a}\right)^{0.25}>12.1 \sqrt{V} \\
12.1 \sqrt{V}, & \text { if } 2.38\left(t_{c l}-t_{a}\right)^{0.25}<12.1 \sqrt{V}\end{cases} \\
f_{c l}=\left\{\begin{array}{l}
1.00+1.290 /_{c l} \text { for } \\
I_{c l} \leq 0.078 \mathrm{~m}^{2} \mathrm{KWW} \\
1.05+0.645 /_{c l} \text { for } \\
I_{c l}>0.078 \mathrm{~m}^{2} \mathrm{KWW}
\end{array}\right\}
\end{gathered}
$$

Where $\quad$ M: metabolic rate $\left(\mathrm{W} / \mathrm{m}^{2}\right)$

(5)

$\mathrm{W}$ : external work $\left(\mathrm{W} / \mathrm{m}^{2}\right)$ (assumed to be 0$)$,

$I_{c l}$ : clothing insulation

$f_{c l}$ : clothing factor, ta: air temperature $\left({ }^{\circ} \mathrm{C}\right)$

$t_{r}$ : mean radiant temperature $\left({ }^{\circ} \mathrm{C}\right)$,

$\mathrm{v}:$ air velocity $(\mathrm{m} / \mathrm{s})$

$P_{a}$ : vapor pressure of air $(\mathrm{kPa})$

$h_{c}$ : convective heat transfer coefficient $\left(\mathrm{W} /\left(\mathrm{m}^{2} \mathrm{~K}\right)\right)$

$t_{c l}$ : surface temperature of clothing $\left({ }^{\circ} \mathrm{C}\right)$ 
e: Euler's number (2.718)

The PMV model has a seven-point scale see Erro! Fonte de referência não encontrada.; it's recommended that the PMV value should lie within -0.5 to +0.5 to ensure the best thermal comfort by most occupants.

Table 2: PMV thermal sensation scale

\begin{tabular}{cc}
\hline PMV & Sensation \\
\hline+3 & Hot \\
+2 & Warm \\
+1 & Slightly warm \\
0 & Neutral \\
-1 & Slightly cool \\
-2 & Cool \\
-3 & Cold \\
\hline
\end{tabular}

\subsection{Energy prediction}

The energy prediction in this study based on the generation and ML training of multiple synthetic data of a specific space in the building. The Design builder has been used to generate an hourly prediction of PMV index, Indoor Air Temperature, indoor Relative Humidity, and energy consumption for one year. An ML regression model using the decision forest algorithm presented by (Criminisi et al., 2012) is used to train the generated synthetic data of the energy simulation. Then, the trained data from the regression model was used to predict the energy consumption of the indoor environment based on the collected environmental attributes from the distributed IoT thermal comfort sensors (see Figure 4) the overview of the energy prediction workflow.

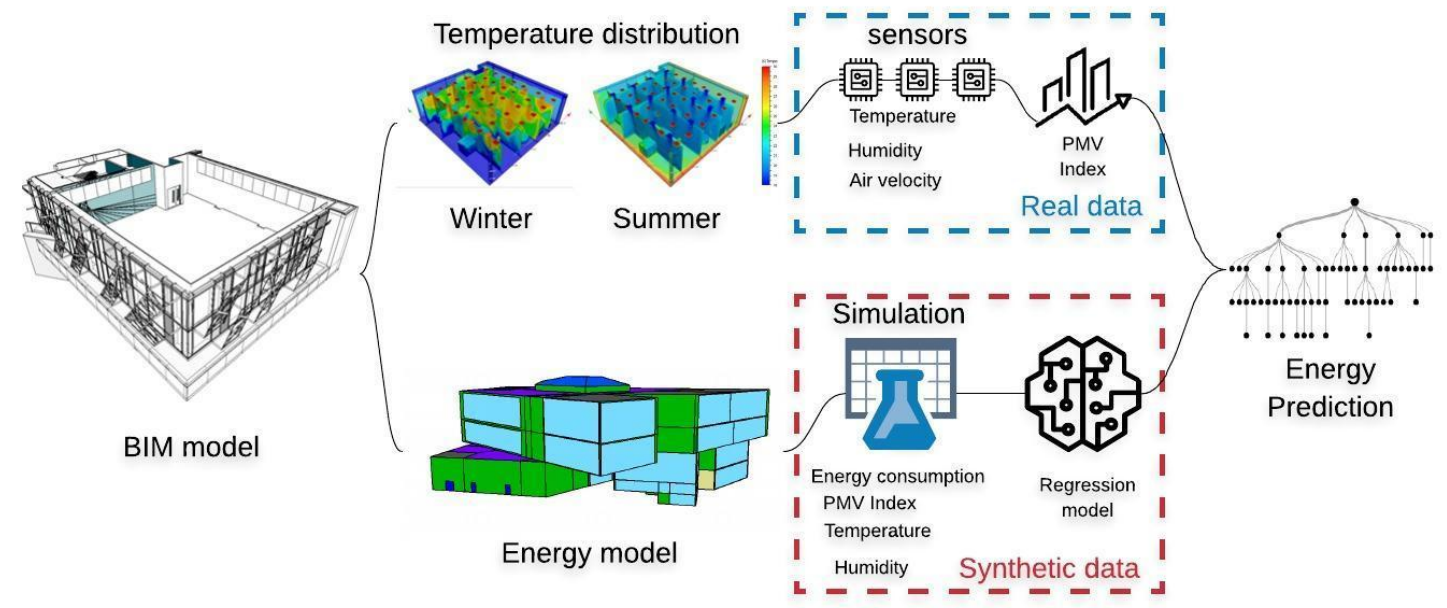

Figure 4: Overview of energy prediction workflow

\section{IMPLEMENTATION AND RESULTS}

The proposed approach implemented in a postgraduate (PGR) office environment at a University of Huddersfield, UK, where occupants are acting naturally without any 
interference by the researcher. The office is about $240 \mathrm{~m} 2$. The main activity is stationary office work. The ventilation system includes a heat recovery unit (HRU). Several CFD simulations have been performed to understand the temperature distribution of the space in the peak climate conditions in winter and summer. The heat map of the temperature distribution in the studied indoor environment can support the decision of placing the thermal comfort sensor see 'Figure 4'. However, in this experiment only one sensor has been used.

The energy model has been developed for the entire building considering orientation, construction properties, opening, and HVAC systems in the building. During the execution of the energy simulation, only PGR office is measured for energy use, air temperature, radiant temperature, relative Humidity, and Fanger PMV. The implementation of the decision forest regression model requires training and testing data. Thus, the data from energy simulation has been divided into two sets $70 \%$ used in the training and $30 \%$ for testing. The results from the trained model have displayed the mean absolute error is 0.676479 , and the coefficient of determination is 0.914263 . Comparing the results from prediction and original data from the simulation, it shows some false in the prediction see 'Figure 5'. This can be fixed by adding more parameter and generating more dataset for training.
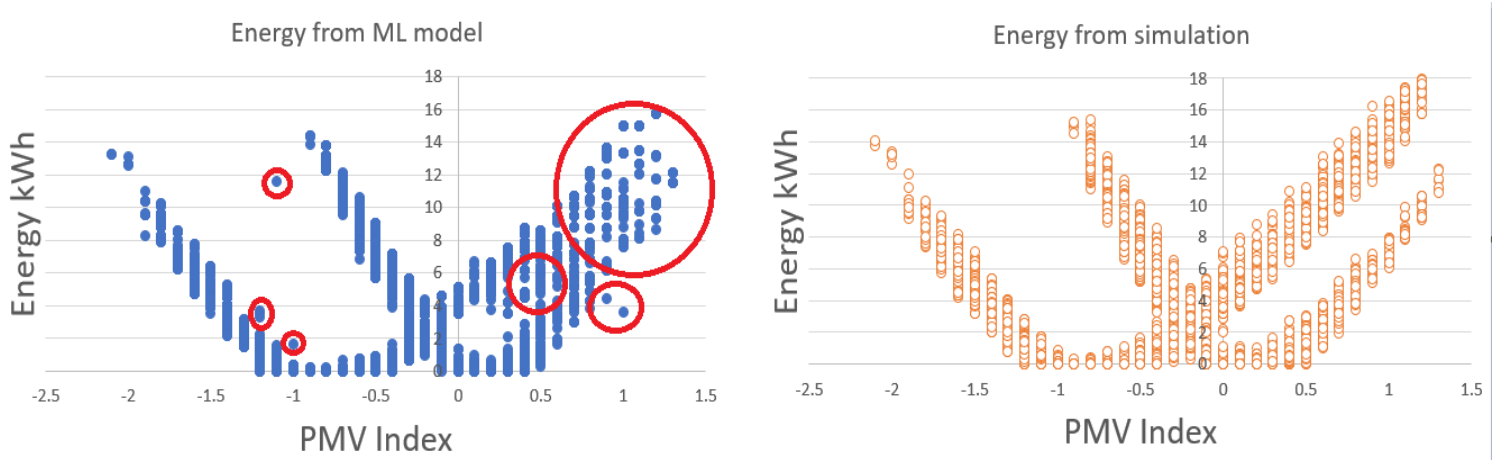

Figure 5: Compare the results from prediction and simulation

\section{CONCLUSION}

In this study, a thermal comfort model sensor has been developed to predicted occupants' thermal satisfaction within the indoor environment. Three sensors used to collect environmental parameters, temperature, humidity, and air velocity. A Wi-Fi module to receive and transmit the sensors data to a cloud database. An online developed thermal comfort evaluation model is used to calculate PMV values in real-time. The system also includes ML trained model to predict the amount of energy used for heating and cooling in the indoor environment.

The output of the presented approach comprises two types of data real and synthetic. The real data are captured from the indoor environment. These data are being collected from the developed thermal comfort sensors. The synthetic data generated from energy simulation include hourly energy performance, indoor climate, and thermal comfort of the studied environment. The ML decision forest regression algorithm is used to predict energy use. The experiment has some limitation which can be listed as follows:

- Using one thermal comfort sensor is not adequate to accurately estimate thermal comfort in the studied environment, the CFD simulation has shown multiple thermal zones need to be included in the study. 
- The mean absolute error of the trained model is not good enough for an accurate prediction and it has some false prediction. Hence, it requires more data to improve the accuracy of the prediction.

- The thermal comfort sensor is consuming more energy than expected. The developed system is transmitting data every 30 seconds, and that would make the power bank loses its power in less than four days.

Future work will focus on improving the ML prediction model by providing more synthetic data. Parametric simulation is going to be considered to build an optimization model to predict the optimum environmental attribute to minimize energy use for heating and cooling.

\section{REFERENCES}

ABDALLAH, M., CLEVENGER, C., VU, T. \& NGUYEN, A. Sensing occupant comfort using wearable technologies. Construction Research Congress 2016, 2016. 940-950.

ARCHITECURE2030. 2018. The 2030 Challenge [Online]. Architecure 2030: Architecure 2030.org. Available: https://architecture2030.org/2030_challenges/2030-challenge/ [Accessed 5/10/2018].

ASADI, E., DA SILVA, M. G., ANTUNES, C. H. \& DIAS, L. 2012. Multi-objective optimization for building retrofit strategies: A model and an application. Energy and Buildings, 44, 81-87.

ASIF, M., MUNEER, T. \& KELLEY, R. 2007. Life cycle assessment: A case study of a dwelling home in Scotland. Building and environment, 42, 1391-1394.

BECERIK-GERBER, B., JAZIZADEH, F., LI, N. \& CALIS, G. 2011. Application areas and data requirements for BIM-enabled facilities management. Journal of construction engineering and management, 138, 431-442.

BROOKS, J., KUMAR, S., GOYAL, S., SUBRAMANY, R. \& BAROOAH, P. 2015. Energyefficient control of under-actuated HVAC zones in commercial buildings. Energy and Buildings, 93, 160-168.

CHANTRELLE, F. P., LAHMIDI, H., KEILHOLZ, W., EL MANKIBI, M. \& MICHEL, P. 2011. Development of a multicriteria tool for optimizing the renovation of buildings. Applied Energy, 88, 1386-1394.

CHUA, K., CHOU, S., YANG, W. \& YAN, J. 2013. Achieving better energy-efficient air conditioning-a review of technologies and strategies. Applied Energy, 104, 87-104.

CORGNATI, S. P., FABRIZIO, E. \& FILIPPI, M. 2008. The impact of indoor thermal conditions, system controls and building types on the building energy demand. Energy and buildings, 40, 627-636.

COSTA, A., KEANE, M. M., TORRENS, J. I. \& CORRY, E. 2013. Building operation and energy performance: Monitoring, analysis and optimisation toolkit. Applied Energy, 101, 310-316.

CRIMINISI, A., SHOTTON, J. \& KONUKOGLU, E. 2012. Decision forests: A unified framework for classification, regression, density estimation, manifold learning and semi-supervised learning. Foundations and Trends ${ }^{\circledR}$ in Computer Graphics and Vision, 7, 81-227.

DOE 2010. Buildings Energy Data Book. In: OFFICE OF ENERGY EFFICIENCY AND RENEWABLE ENERGY, U. S. D. O. E. (ed.). Washington, DC, USA (2010): U.S. Department of Energy. 
DONG, B., PRAKASH, V., FENG, F. \& O'NEILL, Z. 2019. A review of smart building sensing system for better indoor environment control. Energy and Buildings, 199, 2946.

FANGER, P. O. 1970. Thermal comfort. Analysis and applications in environmental engineering. Thermal comfort. Analysis and applications in environmental engineering.

FRONTCZAK, M. \& WARGOCKI, P. 2011. Literature survey on how different factors influence human comfort in indoor environments. Building and environment, 46, 922-937.

GUBBI, J., BUYYA, R., MARUSIC, S. \& PALANISWAMI, M. 2013. Internet of Things (IoT): A vision, architectural elements, and future directions. Future generation computer systems, 29, 1645-1660.

HUDSON, R. \& VELSACO, R. 2018. Modelling and Representing Climatic Data in the Tropics: A Web Based Pilot Project for Colombia. Humanizing Digital Reality. Springer.

JOUDI, A., SVEDUNG, H., CEHLIN, M. \& RÖNNELID, M. 2013. Reflective coatings for interior and exterior of buildings and improving thermal performance. Applied energy, 103, 562-570.

LAM, J. C. \& HUI, S. C. 1996. Sensitivity analysis of energy performance of office buildings. Building and environment, 31, 27-39.

LINHART, F. \& SCARTEZZINI, J.-L. 2011. Evening office lighting-visual comfort vs. energy efficiency vs. performance? Building and Environment, 46, 981-989.

LIU, Y., WANG, L., LIU, J. \& DI, Y. 2013. A study of human skin and surface temperatures in stable and unstable thermal environments. Journal of Thermal Biology, 38, 440-448.

MA, Z., REN, H. \& LIN, W. 2019. A review of Heating, Ventilation and Air Conditioning technologies and innovations used in solar-powered net zero energy Solar Decathlon houses. Journal of Cleaner Production, 118158.

MARY REENA, K. E., MATHEW, A. T. \& JACOB, L. 2018. A flexible control strategy for energy and comfort aware HVAC in large buildings. Building and Environment, 145, 330-342.

NGUYEN, T. A. \& AIELLO, M. 2013. Energy intelligent buildings based on user activity: A survey. Energy and buildings, 56, 244-257.

PAN, D., CHAN, M., DENG, S. \& LIN, Z. 2012. The effects of external wall insulation thickness on annual cooling and heating energy uses under different climates. Applied Energy, 97, 313-318.

PÉREZ-LOMBARD, L., ORTIZ, J. \& POUT, C. 2008. A review on buildings energy consumption information. Energy and buildings, 40, 394-398.

SARDINI, E. \& SERPELLONI, M. 2010. Self-powered wireless sensor for air temperature and velocity measurements with energy harvesting capability. IEEE Transactions on Instrumentation and Measurement, 60, 1838-1844.

SCHIAVON, S., HOYT, T. \& PICCIOLI, A. Web application for thermal comfort visualization and calculation according to ASHRAE Standard 55. Building Simulation, 2014. Springer, 321-334.

YUN, J. \& WON, K.-H. 2012. Building environment analysis based on temperature and humidity for smart energy systems. Sensors, 12, 13458-13470. 